\title{
Research on the Design of Automation System of Distribution and Packaging of Cigarettes
}

\author{
Wei Qun ${ }^{1, a^{*}}$, Tu Xiaofan ${ }^{2, b}$ \\ ${ }^{1}$ School of Art and Design, Wuhan Institute of Technology, Wuhan, 430205,China \\ ${ }^{2}$ Hubei Provincial Branch, China National Tobacco Corporation, Wuhan, 430030, China \\ a33921141@qq.com, btuxiaofan@gmail.com
}

Keywords: cigarettes; distribution; packaging automation; plastic-envelope machine; system design Abstract. The paper studies a set of fast automatic cigarette packaging plan based on plastic-envelope machine which is used to solve packaging problems in the last one kilometers' distribution to retailers. According to the packaging principle of box, group, bar and bag in cigarettes industry, design a packaging plan with bar as main packaging unit, recyclable plastic-envelope film as packaging medium and the order of one retailer as packing unit which finishes packaging plan through automatic packaging machine. Use plastic-envelope film and automatic packaging machine to finish packaging according to the order of one retailer, then the original bottleneck of selection line is solved. Cigarettes industry is badly in need of a set of environment-friendly and fast packaging plan to solve the packaging problem in the last one kilometers' distribution to retailers after the wide adoption of selection line and the construction of logistics center by it. The plan in the paper can solve the problem.

The packaging units of cigarettes have four levels including "box", "group”, "bar" and "bag”. Generally, one bag contains 20 cigarettes, one bar contains 10 bags, one group contains 50 bars and one box contains 5 groups. Cigarette factory generally sends cigarettes to cigarette company by box or group, then cigarette company takes box and group apart by selection line and distributes cigarettes to retailers by bar according to their orders and big orders are distributed by group.

The packaging plan in the paper is designed for the link of cigarettes company to retailers which is an automatic packaging plan adopted by cigarettes company in second packaging with retailer as unit after passing selection line and doesn't include the packaging of whole group delivery (generally, the delivery of whole group doesn’t need second packaging).

\section{The Design of Automatic Packaging Plan}

The main content of the automatic packaging plan includes system structure and work procedures. The main body of automatic packaging equipment consists of four parts: storage belt for bars sorting, piler, sealing and cutting machine and heat shrink machine.

According to the stock size of cigarette packaging from the exit of selection line, the design is as follows:

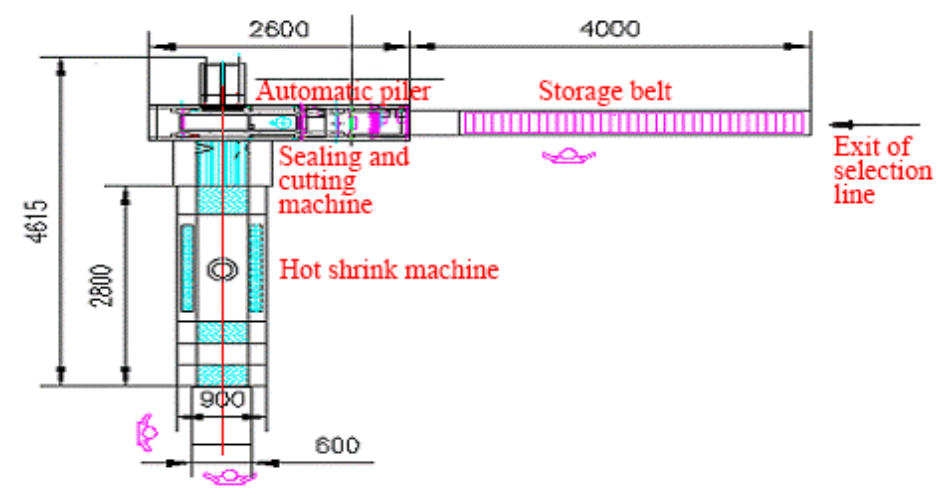

Figure 1. The size of each part and the whole layout 


\section{Main Equipment of Automatic Packaging Line}

\subsection{Storage belt for bars sorting}

The belt linked to the rear end of code spurting belt can make vertical cigarettes fall down so that cigarettes can enter automatic piler smoothly. Different clients have different order structures and the number of bars from the exit of selection equipment is uncertain, so automatic piler can't handle them timely, a lot of cigarettes remain on belt and the exit of selection line is blocked when several big orders come; and when several small orders come consecutively, the whole packaging system can't reach its optimum working state[1]. In order to improve selection and packaging efficiency, cigarettes sorting and storage belt is installed at the front end of automatic piler; when several big orders come consecutively, some cigarettes will remain on storage belt which not only eases the pressure of stacking and packaging but exerts fully the work efficiency of whole packaging system[2].

\subsection{Automatic piler}

After the data of bar packaging is sent to automatic piler, the control unit of automatic piler counts the number of bars in packaging machine and finishes the vertical stacking of bars with five bars as a unit. Vertical stacking with five layers as a unit can achieve the stacking of random combination of 1-25 bars. The entrance adopts o-shaped belt transmission to send bars to the inside of packaging machine. Cigarettes are sent to pushing platform through removing transmission after the stacking of single bag. Packaging data is obtained by PLC control system from software system of selection line which determines the number of bars needing to be packed and displays the current packaging information and work state of equipment on text displayer of piler[3].

2.3. Heat shrink machine of plastic film

Plastic film packaging unit consists of two parts including plastic film seal-cutting part and heat shrink oven part. It consists of the following parts.

The part can finish the bagging and shrinking packaging of piles of bars. Use $0.3-0.6 \mathrm{~mm}$ PE film in packaging. Temperature, sealing time and other parameters about sealing are adjustable. Push cigarettes to plastic film machine through air cylinder of stacking, wrap cigarettes with film through the seal-cutting of melting knife, and send the well-packaged cigarettes to shrink oven through conveyor belt and the conveyor belt of shrink oven, PE film shrinks and wraps bars tightly after being heated in oven. Shrink oven adopts silicon tube which is durable and can't burn film. Some products in current market adopt conveyor chain or wire mesh belt made of teflon materials which is not durable and needs to be replaced frequently[6].

\section{Operating principle of system}

Cigarettes distribution and packaging automation system is a system based on plastic-envelop machine which consists of pneumatic mechanical equipment, PLC and relevant control circuits. Generally, execution unit includes air cylinder and electric machine and magnetic valve is used to control the forwarding and backing of system. PLC can detect the position of air cylinder through sensor and calculate the next distance of forwarding and backing through programs after getting position information to drive air cylinder to the wanted position.

After packaging system is started, cigarettes enter packaging system through conveyor belt driven by electric machine, then work process starts. Conveyor belt has differential system which can adjust the distance among bars and align them. The photoelectric sensor on conveyor belt can detect bars when they come and sends signals to PLC. The system calculates the plan of air cylinder driving process lamination of bars needs according to the preset procedures and sends control signals to magnetic valve through PLC to make magnetic valve of lamination drive air cylinder of lamination to finish pushing, direction change and other lamination actions[7].

After the process of lamination codes placement of bars, PLC sends resetting signals to magnetic valve of lamination and air cylinder of lamination according to the preset procedures to make it restore its original state. Then, drive pushing rod and bags pressing system to add laminating film to 
bars, and seal it with melting knife and cut laminating film off after squeezing air out. Further squeeze the air out of and align bars packaged with laminating film after the heating of heat shrink oven. That is the whole circulation process of automatic work of cigarettes distribution and packaging.

\section{The design of control panels}

\subsection{Control panel of piler}

Control panel of piler consists of three parts including text displayer, button and indicator.

Text displayer: its main function is to indicate the number of bars needing to be packed and the number of bars awaiting to be packed. It integrates manual initialization function, manual cigarettes handling function and continuous cigarettes handling function facilitating maintenance of equipment by maintenance personnel.

Button: it includes emergency stopping button and operation button. Emergency stopping button is red mushroom-shaped set button and controls the operation of piler. Piler is in stopping state when the button is pressed down. Operation button is green and controls the starting of piler. Piler starts when operation button is pressed down and emergency stopping button is released.

Indicator: it includes indicator of power source and operation indicator. Indicator of power source is red and when piler is electrified it is on representing packaging machine is electrified. Operation indicator is green and when piler is in operation it is on.

4.2. Control panel of film cut machine

Film cutting machine consists of buttons, control meters and indicators. Buttons include power button, heating button, resetting button, emergency stopping button of film cutting machine, manual/automatic switch, manual pushing and manual seal-cutting.

Power button: it controls the power source of film cutting machine. Control circuit of film cutting machine is electrified after pressing down the button.

Heating button: it controls the power source of heating circuit. Heating circuit is electrified (independent from control source) and heating begins after pressing down the button.

Resetting button: it can reset film cutting machine. When film cutting machine raises the alarm, it can work again only after pressing down resetting button.

Emergency stopping button of film cutting machine: emergency stopping button of film cutting machine is red mushroom-shaped set button and controls the operation of film cutting machine. Film cutting machine is in stopping state after pressing down the button.

Manual/automatic switch: it is a two-position set switch and controls whether the operation method of film cutting machine is in tandem with piler. When the switch is at automation end, film cutting machine is in tandem with piler. When switch is at hand end, film cutting machine separates with piler.

Manual pushing button: it controls cigarettes pushing cylinder to push cigarettes to film cutting machine. When manual/automatic switch is manual gear, cigarettes is pushed to piler; when manual/automatic switch is automatic switch, cigarettes is pushed to piler and packaging is conducted.

Manual seal-cutting button: when manual/automatic switch is manual switch, it is used for film cutting and packaging.

Control meter: it consists of time relay and temperature controller. Time relay controls the time cutter remains at that position when cutter is in position. When time is up, cutter closes and returns to its original position. Temperature controller controls the maximum temperature of cutter. When temperature reaches the designated temperature, it controls film cutting machine to stop heating.

Indicator: it contains buzzer and operation indication. Buzzer raises the alarm and cutter doesn't fall when cutting prevention photoelectric sensor discovers foreign matters on silicon bar. Operation indication represents the operation state of film cutting machine.

4.3. Control panel of shrink oven

There are air switch, heating, cooling, speed adjustment, meter and temperature controller on control panel of shrink oven. Oven is electrified when air switch is closed[9]. 
Heating button: it controls the heating of oven.

Blowing wind button: it controls the operation of blowing wind electrical machine of oven.

Cooling button: it controls the operation cooling fan.

Speed adjustment: it includes operation button and speed regulator. Operation button controls the operation of conveyor chain. And speed regulator controls the speed of conveyor chain.

Meter: it indicates the electric current of oven and objectively reflects the state of heating pipe.

Temperature controller: it controls the temperature of oven. It controls oven to stop heating when the temperature reaches the designated values.

\section{Conclusion}

The automatic packaging plan is more efficient and faster than the traditional plan of transfer box packaging of logistics. Transfer box of logistics can be used repeatedly, but it wastes space and has a low efficiency. It needs the assistance of massive manpower. For example, workers need to take cigarettes out after cigarettes arrive at the store of retailers. After adopting new recycle technology of ethylene composites, laminating sheets can be used repeatedly after being collected and as environment-friendly as transfer box. It can be foresaw that with the construction of regional logistics and distribution center, plastic-envelope machine-based automatic packaging equipment will be popularized further, given there is second packaging link of logistics distribution center in cigarettes industry and even the whole fast moving consumer goods industry.

\section{Acknowledgements}

This paper is based on youth science foundation funded by Wuhan Institute of Technology, project number: Q201504.

\section{References}

[1] XIAO Wei, The Optimization Research and Application of Cigarette Sorting System. PhD thesis, Hunan University, 2011.

[2] YU Xin-yan. Study on Packaging Design Using System Engineering Theory[J]. Packaging Engineering, 2009,(30)4.

[3] WANG Hui. On importance of ergonomics in industrial design[J]. Journal of Suzhou Art and Design Technology Institute. 2006(S1) .

[4] GENG Da-le, YANG Jun-shun, Zhu Hong. The Ergonomics application in product design[J]. Art and design (Theory).2008(08) .

[5] XUE Yao-xu, SU Guo-pin, Wang Dong, Liu Tao, MENG Shao-jun. Design and implementation of tobacco thermal plastic packaging machine oven warning temperature measuring device[J]. Technology and business, 2013(22):310-311.

[6] CHEN Xin. Packaging Environmental Ecology [ M].Changsha: National Defense University Press,2002.

[7] XU Zhe-yi. The control principles and maintain of automatics shrink packaging machine[J].Packaging and Food Machinery. 2005(01) .

[8] HAN Jun, LU Zonghui, HU Weining.Several control methods of stoker positioning[J]Manufacturing Automation. 2015(4) .

[9] ZHANG Youliang, ZHANG Guoan, Gou Xiangming, The Key Technology of Hot Shrink Packaging Machine[J]. Liqueur. Beverage technology equipment. 2011(2). 